\section{Endoscopic treatment of a giant pedunculated angiolipofibroma of the distal duodenum}

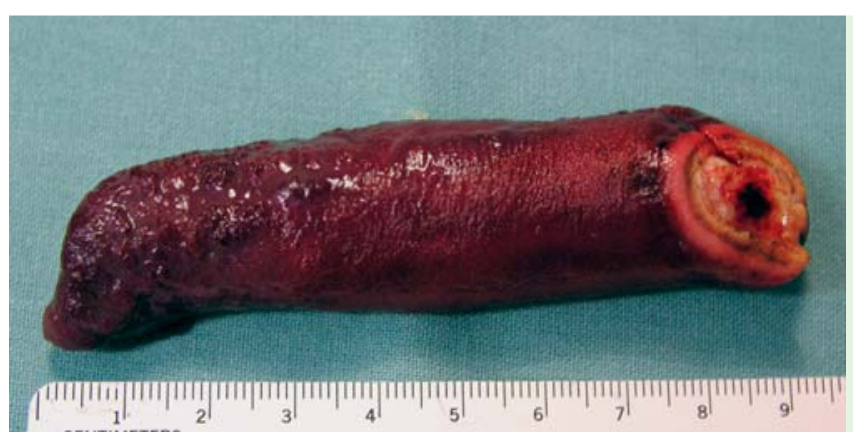

Fig. 1 A giant polyp immediately after endoscopic polypectomy and its retrieval for histology. Note the largecaliber central vessel.

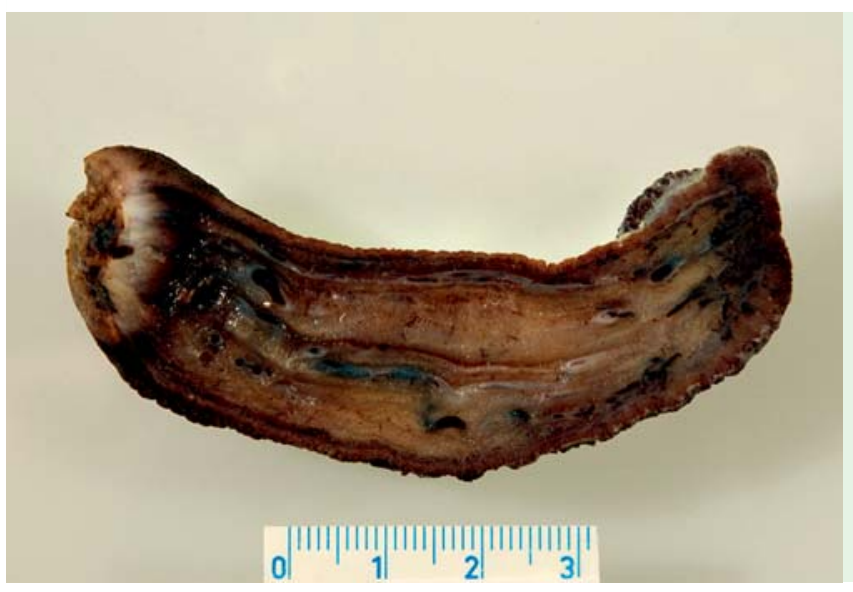

Fig. 2 Longitudinal section of the angiolipofibroma after its fixation in $10 \%$ buffered neutral formalin. Note the large caliber of the vessels.

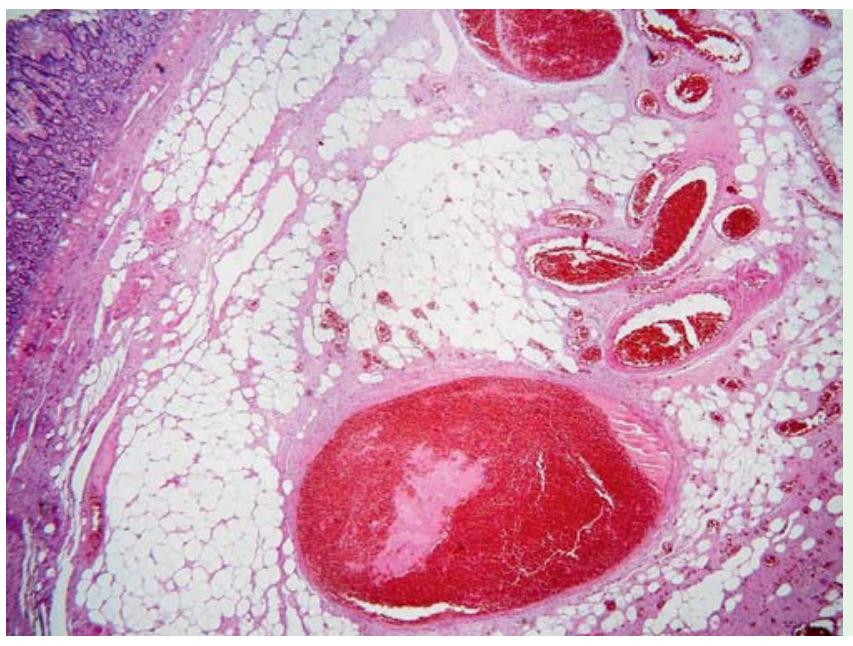

Fig. 3 Histology of angiolipofibroma. A well-demarcated lesion underlies the mucosa. The neoplasm is composed of fat, fibrous tissue, and prominent congested vessels. (Hematoxylin and eosin staining; original magnification $\times 100$.)

Dual antiplatelet therapy (with clopidogrel and aspirin) may be complicated by severe gastrointestinal bleeding [1]. It may unmask an underlying pathology that has been silent so far. Small intestinal bleeding is the most frequent indication for double-balloon enteroscopy (DBE), both for diagnosis and treatment [2,3]. DBE is feasible even for polypectomy of large small-intestinal polyps (e.g. hamarangiolipofibroma.

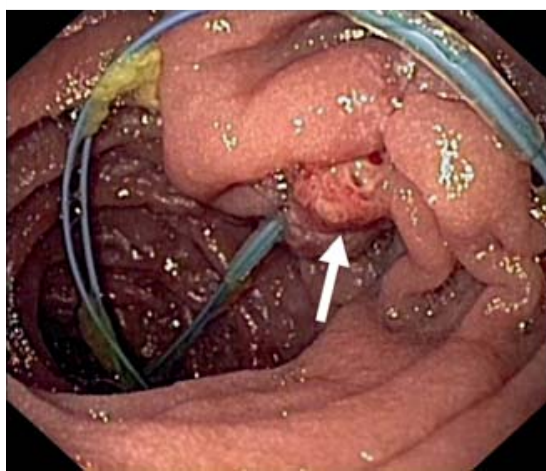

Fig. 4 Control endoscopy 9 days after polypectomy. The healing base is seen in the distal duodenum (arrow), one Endoloop is still in the right position.

enteroscopy with suspicion of small-bowel arteriovenous malformations (AVMs). He was subsequently referred to our department for DBE. However, no AVMs were revealed at DBE. Surprisingly, a finger-like giant polyp growing from the distal part of the duodenum reaching the proximal jejunum was found. The length of the polyp was $12 \mathrm{~cm}$ and its diameter $2 \mathrm{~cm}$. Because of the patient's serious comorbidity, we decided to remove the polyp endoscopically ( $\bullet$ Video 1 ).

The polyp was extracted for histology (- Figs. 1 and 2 ).

The final diagnosis was angiolipofibroma (๑ Fig. 3).

There were no complications after the procedure ( $\bullet$ Fig. 4) and subsequent follow-up was uneventful.

Angiolipofibroma of the gastrointestinal tract is extremely rare. We found only one similar case in the available literature [5]. A giant pedunculated angiolipofibroma of the esophagus in a 62-year-old patient caused slowly deteriorating dysphagia but did not bleed. This was diagnosed by computed tomography and resolved by surgery [5].

Endoscopic polypectomy of giant smallintestinal polyps is a possible alternative to surgery in polymorbid patients. An experienced endoscopist, a safe design of the procedure, and preventive measures (availability of appropriate urgent surgery in case of complications) are necessary conditions.

tomas) [4]. We present an unusual case of successful endoscopic removal of a giant

A 73-year-old man on dual antiaggregation therapy was investigated because of recurrent gastrointestinal bleeding requiring repeated blood transfusions (8 units over 3 months). The patient underwent gastroscopy and colonoscopy elsewhere with normal findings, and capsule

\section{Video 1}

An Endoloop was put over the polyp and secured by two clips. Pure coagulation current was used for cutting. Polypectomy took $8 \mathrm{~min}$ utes. Mild bleeding was controlled by another two Endoloops placed on the base and additional argon plasma coagulation. 


\section{Acknowledgements}

The work was supported by research project MZO 00179906 from the Ministry of Health, Czech Republic.

Endoscopy_UCTN_Code_CCL_1AB_2AZ_3AC

\section{Competing interests: None}

J. Bartova ${ }^{1}$, J. Bures ${ }^{1}$, M. Podhola ${ }^{2}$, S. Rejchrt ${ }^{1}$, I. Tacheci ${ }^{1}$, M. Kopacova ${ }^{1}$

1 2nd Department of Medicine, Charles University in Praha, Faculty of Medicine at Hradec Kralove, University Teaching Hospital, Hradec Kralove, Czech Republic

2 The Fingerland Department of Pathology, Charles University in Praha, Faculty of Medicine at Hradec Kralove, University Teaching Hospital, Hradec Kralove, Czech Republic

\section{References}

1 Roy P, Bonello L, Torguson $R$ et al. Impact of "nuisance" bleeding on clopidogrel compliance in patients undergoing intracoronary drug-eluting stent implantation. Am J Cardiol 2008; 102: 1614-1617

2 Kopacova M, Tacheci I, Rejchrt S et al. Double balloon enteroscopy and acute pancreatitis. World J Gastroenterol 2010; 16: 2331 -2340

3 Rejchrt S, Kopacova M, Tacheci I et al. Interventional double balloon endoscopy for Crohn's, gastrointestinal bleeding, and foreign body extraction. Tech Gastrointest Endosc 2008; 10: 101 - 106

4 Kopacova M, Bures J, Ferko A et al. Comparison of intra-operative enteroscopy and double balloon enteroscopy in the diagnosis and treatment of Peutz-Jeghers syndrome. Surg Endosc 2010; 24: $1904-1910$

5 Koischwitz D. Computertomographische Diagnose eines monströsen gestielten Angiolipofibroms des Ösophagus. [Computed tomographic diagnosis of a monstrous pedunculated angiolipofibroma of the esophagus.] Fortschr Röntgenstr 1988; 149: 105 107

\section{Bibliography}

DOI $10.1055 / \mathrm{s}-0030-1256025$

Endoscopy 2011; 43: E96-E97

(c) Georg Thieme Verlag KG Stuttgart · New York . ISSN 0013-726X

\section{Corresponding author}

\section{Kopacova, MD, PhD}

Second Department of Medicine

Charles University Teaching Hospital

Sokolska 581

50005 Hradec Kralove

Czech Republic

Fax: +420-495-834785

kopaemar@fnhk.cz 